\title{
Intermittent pneumatic compression in patients with postmastectomy lymphedema
}

\section{DARIA DOMINIKA CHMIELEWSKA ${ }^{1, \mathbf{A}, \mathbf{B}, \mathbf{D}}$, MAGDALENA STANIA ${ }^{1, \mathbf{A}, \mathbf{E}}$, EDWARD BŁASZCZAK ${ }^{2, \mathbf{c}}$, KRYSTYNA KWAŚNA ${ }^{1, F}$}

${ }^{1}$ Department of Basics of Physiotherapy, Faculty of Physiotherapy, Academy of Physical Education in Katowice

${ }^{2}$ Chair and Department of Medical Biophysics, Medical University of Silesia in Katowice

A - Study Design, B - Data Collection, C - Statistical Analysis, D - Data Interpretation, E - Manuscript Preparation, $\mathbf{F}$ - Literature Search, $\mathbf{G}$ - Funds Collection

Summary Background. Postmastectomy lymphedema frequently affecting young patients constitutes a personal, family and social problem. For this reason, primary care physicians often consult both patients and their families.

Objectives. The aim of this study was to evaluate the effects of intermittent pneumatic compression (IPC) alone or in combination with exercises on upper limbs circumference and hand function.

Material and methods. The study population consisted of 21 patients with breast cancer-related lymphedema. In Group A, the treatment consisted of 20 IPC sessions ( 45 minutes a day at $60 \mathrm{~mm} \mathrm{Hg}$, 5 times weekly) and physical exercises (combination therapy). Group B only received 20 IPC sessions. Prior to and after intermittent pneumatic compression, all patients had arm circumference measurements at 6 sites on the mastectomy side. Hand function was assessed with the Carpal Tunnel Syndrome Functional Status Scale.

Results. Both groups exhibited a reduction in upper limb circumferences after the therapy in comparison to the initial values. However, a comparison of percentage circumference changes did not show any advantage of the combination therapy on the magnitude of the edema and hand function.

Conclusions. Pneumatic compression is an effective method of reducing upper limb edema in postmastectomy patients. The exercises did not have a significant effect on function of hand.

Key words: breast cancer, intermittent pneumatic compression, lymphedema.

Chmielewska DD, Stania M, Błaszczak E, Kwaśna K. Intermittent pneumatic compression in patients with postmastectomy lymphedema. Fam Med Prim Care Rev 2016; 18(4): 419-424, doi: 10.5114/fmpcr.2016.63694.

\section{Background}

Primary care physicians are an important element in the healthcare system in Poland, since they take care of postmastectomy patients together with oncology and gynecology specialists. Primary care physicians make sure patients undergo regular control, and their visits to other specialists are monitored. It is essential that primary care physicians apply the rules of tertiary prevention in the treatment of postmastectomy patients, the aim of which is to prevent any complications of the disease, i.e. lymphedema of the upper limb. Secondary lymphedema frequently affecting young postmastectomy patients constitutes a personal, family and social problem. For this reason, primary care physicians often consult both patients and their families needing support and recommendations for efficient rehabilitation. The efficiency of physiotherapeutic methods in reducing secondary edema of the upper limb and in preventing any complications is a constant object of interest of many researchers. In this case, the International Society of Lymphology (ISL) recommends conducting complex decongestive therapy - CDT, which includes: manual lymphatic drainage, bandage compression, exercises, patient education and skin protection [1]. CDT is a gold standard in the case of lymphedema [2], and its efficiency was confirmed by various studies $[3,4]$.

The expert opinion presented in the documents of the ISL Consensus shows that intermittent pneumatic compres- sion - IPC is a method of lymphedema preventive treatment specified under point " $b$ ", immediately after complex decongestive therapy [1]. This makes intermittent pneumatic compression a supplementary method. This is valuable in the second (the so-called maintenance) stage of edema treatment.

Complex decongestive therapy requires the means and work, which makes it slightly more expensive. Therefore, in the last few years, pneumatic compression combined with CTD is more frequently used in the treatment of secondary lymphedema $[2,5]$. Pneumatic compression is used as an independent method, e.g. at home [6], and is addressed to a broad spectrum of patients as cheaper and easily accessible [7].

\section{Objectives}

The aim of this study was to evaluate the effects of intermittent pneumatic compression in combination with exercises (group A) on the change in upper limb circumference and hand function in postmastectomy patients with secondary edema, as compared to the results of using pneumatic compression without additional exercises (group B).

\section{Material and methods}

The study was conducted in 2014 at the Rehabilitation Laboratory in Oświęcim. The study population consisted of 
21 patients with breast cancer-related lymphedema. Patients were qualified based on inclusion criteria such as: radical mastectomy not later than 5 years prior, edema of the upper limb on the operated side.

Inclusion criteria included: occurrence of co-morbidities, such as hypertension (above stage 1 hypertension according to $\mathrm{ESH} / \mathrm{ESC}$ ), failure of the cardiovascular system, other types of edema, diabetes, rheumatoid arthritis, dermatitis, collagenosis, cirrhosis, kidney failure, lesions and ulcerations of the swollen limb. The level of lymphedema was evaluated by comparing two circumferences at particular levels of the limb on the mastectomy side and on the healthy side.

It was established, together with the Lymphology Association of North America, that a circumference difference in examined groups below or equal to $3 \mathrm{~cm}$ will be considered as mild edema. Reversibility criteria after limb-lifting were applied according to the International Society of Lymphology (ISL) [1].

Patients were randomly divided into two groups. Group A included 11 women with an average age of 60.45 years (SD 7.34, min. 51 years, max. 72 years). Edema of the upper limb in group A was assessed as mild, since the average circumference difference at almost all of the measured levels was smaller than $3 \mathrm{~cm}$; only at the K3 level (measurement through lateral epicondylitis) did the difference amount to $3.15 \mathrm{~cm}$. According to ISL, edema was classified as stage II, as it was irreversible and unresolved after limb-lifting with a pit occurring under compression. In group $A$, the average time between the surgery and the examination was 4.09 months (SD 1.45). Here, the average time between mastectomy and the occurrence of edema was 8.91 months (SD 2.91). In group A, treatment consisted of 20 intermittent pneumatic compression sessions and physical exercises (every day, 5 times a week) for 4 weeks. Cuff pressure was 60 $\mathrm{mm} \mathrm{Hg}$ and did not cause any discomfort [1].

Patients supplied with compression clothing wore it during exercise, which lasted 40 minutes and included: exercises on rehabilitation pulley systems (non-weight bearing and with weights), continuous training on a cycle ergometer, exercises with manual rotors, chest and shoulder girdle exercises including stations (4 exercises, 3 sets of 10 repetitions, load $50 \%$ CM of maximum strength).

Group B consisted of 10 women whose average age was 61.2 years (SD 5.22, min. 52 years, max. 70 years). Edema of the upper limb in group B was assessed as mild, since the average circumference difference at almost all of the measured levels was smaller than $3 \mathrm{~cm}$; only at the K3 level (measurement through lateral epicondylitis) did the difference amount to $3.13 \mathrm{~cm}$. According to ISL, edema was classified as stage II, as it was irreversible and unresolved after limb-lifting with a pit occurring under compression. In group $B$, the average time between the surgery and the examination was 4 years (SD 1.63). Here, the average time between mastectomy and the occurrence of edema was 8.10 months (SD 2.42). Group $B$ received 20 intermittent pneumatic compression sessions for 4 weeks, with the same parameters as in group A.

A Boa (Metrum CryoFlex) device was used for intermittent pneumatic compression sessions. The cuff was filled sequentially, starting from chambers located distally (around the hand and wrist) in a proximal direction, whereas chambers filled earlier were not subject to deflation (maintained proper pressure). The session lasted 45 minutes.

Hand function in the examined women was evaluated based on the CTS FFS (Carpal Tunnel Syndrome Functional
Status Scale) survey, which contained questions concerning various difficulties during: writing, buttoning clothes, operating a telephone/computer, opening jars, household work, carrying grocery bags, taking a bath or dressing. The aforementioned difficulties were evaluated based on the Likert scale from 1 to 4 ( 1 - no difficulties, 4 - a lot of difficulties). The raw data was transformed into a 0-100 scale based on the formula: transformed result $=$ (obtained raw data - minimal result on the scale/maximum result on the scale - minimal result on the scale) $\times 100$ [8].

For an objective evaluation of treatment results, circumference measurements of the swollen limb on the mastectomy side were performed. Measurements were made twice: 1) before starting treatment, 2) after finishing treatment. In order to evaluate the degree of limb edema on the mastectomy side, the circumference of the hand and upper limb on the mastectomy side was compared with the other side. Circumference was measured with a measuring tape at 6 levels: wrist (K1) - through styloid process of the ulna and radial bone, next $5 \mathrm{~cm}$ higher (K2), and then: measurement through lateral epicondylitis (K3), $10 \mathrm{~cm}$ higher (K4) and 10 $\mathrm{cm}$ below (K5), and in the axillary line (K6). Hand measurements applied to the circumference at the base of phalanx proximalis $1-5(\mathrm{R}-1-5)$ and through metatarsophalangeal articulations (MCP-6) of the hand $[9,10]$. Two reference points were used for the aforementioned measurements, i.e. tips of the small and index finger, so that the second measurement is performed in the exact same place. Measurements were made by a single therapist.

\section{Statistical methods}

The homogeneity of traits characteristic for patients in groups A and B was examined with the use of a two-sided Fisher's test and Mann-Whitney $U$ test (level of statistical significance $p<0.05)$. The average results of hand and upper limb circumference before and after treatment in groups $\mathrm{A}$ and $\mathrm{B}$ were compared with a non-parametric Wilcoxon signed-rank test $(p<0.05)$. The distribution of examined traits was unimodal, and skewness and flatness were smaller than 2.5; therefore, an arithmetic mean and standard deviation are used as measures of central tendency and as measure of dispersion. Relative changes (percentage) in the circumference of the arm and upper limb in both groups were compared after treatment with the Mann-Whitney $U$ test.

\section{Results}

Before treatment, both groups were homogenous (Table 1), also in terms of initial hand and upper limb circumference, degree of edema and limitations in manual activities (CTS FFS).

There are statistically significant differences in hand and upper limb circumference after treatment as compared to its values before treatment (Wilcoxon test) both in group A (Table 2) and group B (Table 3).

Comparison of average percentage changes of circumference after treatment did not confirm the advantage of treatment with pneumatic compression and physical exercises in reducing upper limb edema and improving hand function. No negative effects of physical exercises in women with upper limb lymphedema were observed. 


\begin{tabular}{|c|c|c|c|c|}
\hline Before treatment & Group A & Group B & $p(A, B)$ & test \\
\hline $\begin{array}{l}\text { Average age } \\
\text { (SD) }\end{array}$ & $\begin{array}{l}60.45 \\
(7.34)\end{array}$ & $\begin{array}{l}61.40 \\
(5.44)\end{array}$ & $p>0.05$ & $\begin{array}{l}\text { Mann-Whitney } \\
\text { U test }\end{array}$ \\
\hline Radiotherapy (number of women) & 7 & 8 & $p>0.05$ & \multirow{8}{*}{ 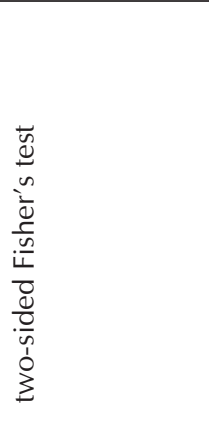 } \\
\hline Chemotherapy (number of women) & 9 & 8 & $p>0.05$ & \\
\hline Hormonal therapy (number of women) & 7 & 6 & $p>0.05$ & \\
\hline History of CDT & 5 & 6 & $p>0.05$ & \\
\hline Work & 5 & 5 & $p>0.05$ & \\
\hline Pension & 2 & 3 & $p>0.05$ & \\
\hline Retirement & 4 & 2 & $p>0.05$ & \\
\hline Mastectomy: on the right/on the left & $4 / 7$ & $2 / 8$ & $\begin{array}{l}p>0.05 \\
p>0.05\end{array}$ & \\
\hline $\begin{array}{l}\text { Edema classification acc. to ISL } \\
\text { Stage II }\end{array}$ & 11 & 10 & $p>0.05$ & \\
\hline $\mathrm{R} 1 *$ average $(\mathrm{SD})$ & $7.65(0.41)$ & $7.62(0.24)$ & $p>0.05$ & \multirow{12}{*}{ 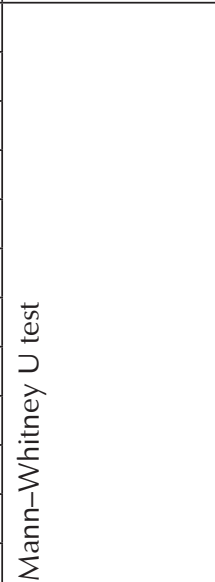 } \\
\hline R2* average $(\mathrm{SD})$ & $7.42(0.56)$ & $7.48(0.26)$ & $p>0.05$ & \\
\hline R3* average (SD) & $7.16(0.57)$ & $7.15(0.34)$ & $p>0.05$ & \\
\hline R4* average (SD) & $6.85(0.58)$ & $6.67(0.28)$ & $p>0.05$ & \\
\hline R5* average (SD) & $6.6(0.51)$ & $6.39(0.21)$ & $p>0.05$ & \\
\hline 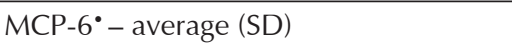 & $20.84(1.25)$ & $20.13(0.54)$ & $p>0.05$ & \\
\hline $\mathrm{K} 1 * *$ average $(\mathrm{SD})$ & $17.78(1.04)$ & $17.74(0.94)$ & $p>0.05$ & \\
\hline $\mathrm{K} 2 * *$ average $(\mathrm{SD})$ & $20.38(2.27)$ & $18.88(1.03)$ & $p>0.05$ & \\
\hline K3** average (SD) & $31.1(3.32)$ & $30.64(2.55)$ & $p>0.05$ & \\
\hline K4** average $(\mathrm{SD})$ & $27.38(1.46)$ & $27.09(1.26)$ & $p>0.05$ & \\
\hline K5** average (SD) & $33.42(2.78)$ & $33.52(1.8)$ & $p>0.05$ & \\
\hline K6** average (SD) & $36.42(2.12)$ & $37.16(2)$ & $p>0.05$ & \\
\hline
\end{tabular}

R1-R5* - finger circumference, MCP-6 ${ }^{*}$ - circumference through metatarsophalangeal articulations, K1-K6** - upper limb circumference.

\begin{tabular}{|c|c|c|c|c|c|c|}
\hline \multicolumn{7}{|l|}{ Group A } \\
\hline \multirow[t]{2}{*}{ Circumference } & \multirow[t]{2}{*}{$\mathbf{N}$} & \multicolumn{2}{|c|}{ Before treatment } & \multicolumn{2}{|c|}{ After treatment } & \multirow[t]{2}{*}{$p$} \\
\hline & & Average & SD & Average & SD & \\
\hline R1 & 11 & 7.65 & 0.41 & 7.55 & 0.39 & 0.0491 \\
\hline R2 & 11 & 7.42 & 0.56 & 7.27 & 0.53 & 0.0440 \\
\hline R3 & 11 & 7.16 & 0.57 & 7.11 & 0.55 & 0.3983 \\
\hline R4 & 11 & 6.85 & 0.58 & 6.73 & 0.54 & 0.0415 \\
\hline R5* & 11 & 6.6 & 0.51 & 6.41 & 0.51 & 0.0166 \\
\hline MCP-6• & 11 & 20.84 & 1.25 & 20.32 & 0.93 & 0.0044 \\
\hline K1 & 11 & 17.78 & 1.04 & 16.56 & 1 & 0.0418 \\
\hline K2 & 11 & 20.38 & 2.27 & 19.72 & 2.38 & 0.0125 \\
\hline K3 & 11 & 31.1 & 3.42 & 29.64 & 2.48 & 0.0033 \\
\hline K4 & 11 & 27.38 & 1.46 & 27.03 & 1.41 & 0.0911 \\
\hline K5 & 11 & 33.42 & 2.78 & 31.5 & 2.38 & 0.0500 \\
\hline K6** & 11 & 36.42 & 2.12 & 34.86 & 1.91 & 0.0058 \\
\hline
\end{tabular}

Wilcoxon test. R1-R5* - finger circumference, MCP-6 - circumference through metatarsophalangeal articulations, $\mathrm{K} 1-\mathrm{K} 6^{* *}-\mathrm{upper}$ limb circumference. 


\begin{tabular}{|c|c|c|c|c|c|c|}
\hline \multicolumn{7}{|l|}{ Group B } \\
\hline \multirow[t]{2}{*}{ Circumference } & \multirow[t]{2}{*}{$\mathbf{N}$} & \multicolumn{2}{|c|}{ Before treatment } & \multicolumn{2}{|c|}{ After treatment } & \multirow[t]{2}{*}{$p$} \\
\hline & & Average & SD & Average & SD & \\
\hline R1 & 10 & 7.62 & 0.24 & 7.46 & 0.21 & 0.1141 \\
\hline R2 & 10 & 7.48 & 0.26 & 7.28 & 0.27 & 0.0108 \\
\hline R3 & 10 & 7.15 & 0.34 & 7.03 & 0.31 & 0.1668 \\
\hline R4 & 10 & 6.67 & 0.28 & 6.58 & 0.19 & 0.1925 \\
\hline R5* & 10 & 6.39 & 0.21 & 6.19 & 0.19 & 0.0125 \\
\hline MCP-6 ${ }^{\circ}$ & 10 & 20.13 & 0.54 & 20.04 & 0.59 & 0.5408 \\
\hline K1 & 10 & 17.74 & 0.94 & 17.25 & 0.61 & 0.0284 \\
\hline K2 & 10 & 18.88 & 1.03 & 18.24 & 0.72 & 0.0108 \\
\hline K3 & 10 & 30.64 & 2.55 & 29.01 & 1.85 & 0.0051 \\
\hline K4 & 10 & 27.09 & 1.26 & 26.39 & 0.78 & 0.0414 \\
\hline K5 & 10 & 33.52 & 1.8 & 32.48 & 2 & 0.0744 \\
\hline K6** & 10 & 37.16 & 2 & 35.7 & 1.54 & 0.0050 \\
\hline
\end{tabular}

Wilcoxon test. R1-R5* - finger circumference, MCP- $6^{*}$ - circumference through metatarsophalangeal articulations, $\mathrm{K} 1-\mathrm{K} 6^{* *}-\mathrm{upper}^{*}$ limb circumference.

\section{Discussion}

Breast cancer is a common type of cancer among women. Data from the National Cancer Registry shows that every year, the number of women with breast cancer increases [11].

Mastectomy and radiotherapy frequently result in upper limb lymphedema on the mastectomy side. Secondary lymphedema occurs from 2 to 92 months after the date of surgery. Edema influences the physical part of a patient's life: limitations of joint movement or pain, as well as in the mental sphere, such as depression, discouragement, which decreases the quality of women's life and their functioning.

The cross-sectional study included 57 postmastectomy patients, which were divided into two groups according to the presence or lack of hand edema. Functional hand tests (Kapandji index) and measurements of kinesthetic sense were performed, and a questionnaire examining hand function in everyday life was completed (Hand Function Sort). It was observed that with the increase of hand edema, the patient's manual hand skills, kinesthetic sense and everyday operation [12] decreased. The presented study focuses on examining hand function in patients with lymphedema before and after treatment. The CTS FFS (Carpal Tunnel Syndrome Functional Status Scale) was used to evaluate the limitations in everyday activities caused by hand edema. This tool was selected due to a limited number of validated questionnaires in Polish. There is no significant improvement in hand function in both groups after treatment as compared to the results before treatment. The only result was an improvement in group A in performing everyday activities. It seems that the selected tool is not sensitive enough in the case of patients with hand edema.

Physical exercises are aimed at improving general efficiency and decreasing body weight [13]. Exercises increase joint mobility and improve the functioning of the cardiovascular system and muscle strength, also in the swollen upper limb. Exercises in water may help reduce the edema [13]. Comparison of the results of resistance and aerobic exercises in postmastectomy patients with a group of patients not participating in physical exercise showed a significant increase of respiratory parameters $\left(\mathrm{V} \cdot \mathrm{O}_{2 \max }\right)$ of muscle strength in upper and lower limbs (measured as the number of exercise repetitions with the set reference value) and improvement in the quality of life (QLQ C30) [14].
ISL recommends that physical exercises in patients with lymphedema are less intense and shorter [1]. Patients are recommended to do the following: resistance exercises, weight training, endurance exercises, aerobics or yoga [15]. Exercises may become more intense with time, provided that symptoms of edema are not intensified [16]. Weight training performed in stations, consisting of 3 sets of 10 repetitions for the chest muscles, shoulder girdle and lower limbs, done under the supervision of a therapist, did not increase the risk of lymphedema in postmastectomy patients [17] during 12 months of observation.

A series of studies conducted by prof. Olszewski showed that in order to generate an effective pressure of tissue fluid (pressure gauges placed subcutaneously) in the case of lower limb edema of the II-IV degree, we need even $50 \mathrm{sec}$ onds and higher pressure $(120 \mathrm{~mm} \mathrm{Hg}$ around the ankle), while preserving a proximal pressure gradient of 20\% [7]. Lymphoscintigraphy revealed that pneumatic compression clearly transfers a lot of fluid towards the groin, although the authors also indicate that methods of facilitating the flow of fluid towards tissues that are not swollen and increasing local reabsorption [18] remains unknown. In 18 patients with one-sided edema II-IV (without venous components), pneumatic compression conducted for 24-36 months (45 minutes, pressure: $120 \mathrm{~mm} \mathrm{Hg}$, inflation time: 50 seconds for each chamber) influenced a gradual reduction of lower limb circumference and leads to an increase in the flexibility of tissue without any side effects [19].

However, it should be emphasized that the results of studies conducted under the supervision of prof. Olszewski applied only to the lower limbs in patients with post-traumatic or post-inflammatory lymphedema; therefore, the conclusions of such studies cannot be applied in the case of the upper limb. The value of pneumatic compression pressure in treatment of the upper limb is: $40 \mathrm{~mm} \mathrm{Hg}$ [10], $50 \mathrm{~mm} \mathrm{Hg}$ [20] or $30 \mathrm{~mm} \mathrm{Hg}$ [6], which corresponds to the values of 30-60 $\mathrm{mm} \mathrm{Hg}$ [1] recommended by ISL. In the aforementioned paper, a cuff pressure of $60 \mathrm{~mm} \mathrm{Hg}$ was used, which significantly influenced the changes in hand and upper limb circumference on the mastectomy side. Pneumatic compression procedures proved efficient in circumference reduction. However, non-weight bearing exercises of the upper limb did not intensify the effect of circumference reduction.

The studies of Szuba et al. confirmed the efficiency of combining pneumatic compression $(40-50 \mathrm{~mm} \mathrm{Hg}$ ) with CTD in reducing lymphedema of the upper limb in postmastecto- 
my patients and in increasing joint movement. The results in this group were significantly better than in the second group, where CTD [20] was used. However, other studies did not bring about any additional benefits of combining treatment with pneumatic compression for lymphedema [10] reduction.

Intermittent pneumatic compression as an independent method of home treatment of edema in patients with chronic venous insufficiency seems more effective than manual lymphatic drainage performed by a therapist [22]

The studies of Brayton et al., which are based on data from the U.S. patient registry for the years 2007-2012 on patients treated for cancer with complications in the form of lymphedema, showed that the costs of treatment for two 12-month periods, before and after pneumatic compression, significantly decreased (by 18\%) in the period when pneumatic compression was applied. Such compression provides much more access to treatment as compared to e.g. manual lymphatic drainage [23].

\section{Limitations}

Our study was limited by the small number of examined patients and measurements of limb circumference only. Mea- surements of limb circumference are used by other researchers $[5,9,19,21]$. In the studies of Moattari et al., volumetric measurements were performed together with circumference measurements, based on which a high correlation coefficient from 0.80 to 0.92 was obtained for measurements on the olecranon level, then at 10, 15 and $20 \mathrm{~cm}$ below and above the olecranon [5]. A similar satisfactory correlation was obtained between measurements of circumference at 4 and 10 levels and through plethysmography. The authors of the aforementioned studies show that the metric method is simple and can be applied in evaluating the results of edema treatment [9].

\section{Conclusions}

Pneumatic compression is an effective method of reducing upper lymphoedema in postmastectomy patients. Exercises did not have a significant effect on hand function.

Acknowledgements. We would like to thank mgr Łukasz Matyjaszczyk for his help in taking the measurements.

Source of funding: This work was funded by the authors' resources.

Conflict of interest: The authors declare no conflict of interests.

\section{References}

1. The diagnosis and treatment of peripheral lymphedema: 2013 Consensus Document of the International Society of Lymphology. Lymphology 2013; 46(1): 1-11.

2. Szolnoky G, Dobozy A, Kemény L. Towards an effective management of chronic lymphedema. Clin Dermatol 2014; 32(5): 685-691.

3. Dayes IS, Whelan TJ, Julian JA, et al. Randomized trial of decongestive lymphatic therapy for the treatment of lymphedema in women with breast cancer. J Clin Oncol 2013; 31(30): 3758-3763.

4. Tambour M, Tange B, Christensen R, et al. Effect of physical therapy on breast cancer related lymphedema: protocol for a multicenter, randomized, single-blind, equivalence trial. BMC Cancer 2014; 3(14): 239.

5. Moattari M, Jaafari B, Talei A, et al. The effect of combined decongestive therapy and pneumatic compression pump on lymphedema indicators in patients with lymphedema secondary to breast cancer treatment: a randomized clinical control trial. Breast J 2013; 19(1): 114-115.

6. Fife CE, Davey S, Maus EA, et al. A randomized controlled trial comparing two types of pneumatic compression for breast cancerrelated lymphedema treatment in the home. Support Care Cancer 2012; 20(12): 3279-3286.

7. Zaleska $M$, Olszewski WL, Jain $\mathrm{P}$, et al. Pressures and timing of intermittent pneumatic compression devices for efficient tissue fluid and lymph flow in limbs with lymphedema. Lymphat Res Biol 2013; 11(4): 227-232.

8. Chmielewska D, Jeruszka S, Błaszczak E, et al. Ocena jakości życia u kobiet po mastektomii z obrzękiem limfatycznym. Rehabil Prakt 2012; 1(Supl. Limfologia w Praktyce): 18-22.

9. Brorson H, Höijer P. Standardised measurements used to order compression garments can be used to calculate arm volumes to evaluate lymphoedema treatment. J Plast Surg Hand Surg 2012; 46(6): 410-415.

10. Uzkeser H, Karatay S, Erdemci B. Efficacy of manual lymphatic drainage and intermittent pneumatic compression pump use in the treatment of lymphedema after mastectomy: a randomized controlled trial. Breast Cancer 2015; 22(3): 300-307.

11. Krajowy Rejestr Nowotworów [cited: 10.10.2015]. Avaible from URL: http://onkologia.org.pl/raporty/.

12. Karadibak D, Yavuzsen T. Evaluation of kinesthetic sense and hand function in women with breast cancer-related lymphedema. J Phys Ther Sci 2015; 27(6): 1671-1675.

13. Fernández-Lao C, Cantarero-Villanueva I, Ariza-Garcia A, et al. Water versus land-based multimodal exercise program effects on body composition in breast cancer survivors: a controlled clinical trial. Support Care Cancer 2013; 21(2): 521-530.

14. Herrero F, San Juan AF, Fleck SJ, et al. Combined aerobic and resistance training in breast cancer survivors: a randomized, controlled pilot trial. Int J Sports Med 2006; 27(7): 573-580.

15. Fong DY, Ho JW, Hui BP, et al. Physical activity for cancer survivors: meta-analysis of randomised controlled trials. BMJ 2012; 344:e70, doi: 10.1136/bmj.e70.

16. Baumann FT, Bloch W, Weissen A, et al. Physical activity in breast cancer patients during medical treatment and in the aftercare - a review. Breast Care (Basel) 2013; 18(5): 330-334.

17. Schmitz KH, Ahmed RL, Troxel AB, et al. Weight lifting for women at risk for breast cancer-related lymphedema: a randomized trial. JAMA 2010; 304(24): 2699-2705.

18. Olszewski WL, Cwikla J, Zaleska M, et al. Pathways of lymph and tissue fluid flow during intermittent pneumatic massage of lower limbs with obstructive lymphedema. Lymphology 2011; 44(2): 54-64.

19. Zaleska M, Olszewski WL, Durlik M. The effectiveness of intermittent pneumatic compression in long-term therapy of lymphedema of lower limbs. Lymphat Res Biol 2014; 12(2): 103-109.

20. Szuba A, Achalu R, Rockson SG. Decongestive lymphatic therapy for patients with breast carcinoma-associated lymphedema. A randomized, prospective study of a role for adjunctive intermittent pneumatic compression. Cancer 2002; 95(11): 2260-2267 .

21. Mondry TE, Riffenburgh RH, Johnstone PA. Prospective trial of complete decongestive therapy for upper extremity lymphedema after breast cancer therapy. Cancer J 2004; 10(1): 42-48. 
22. Śmiłowska A, Skorupińska A, Gromek K, et al. Czy przerywana kompresja pneumatyczna w warunkach domowych może być bardziej przydatna w redukcji obrzęku chłonnego kończyn dolnych u chorych z przewlekłą niewydolnością żylna niż manualny drenaż limfatyczny wykonany w przychodni? Wskazówki praktyczne dla lekarzy rodzinnych. Fam Med Prim Care Rev 2015; 17(3): 219-224.

23. Brayton KM, Hirsch AT, O Brien PJ, et al. Lymphedema prevalence and treatment benefits in cancer: impact of a therapeutic intervention on health outcomes and costs. PLoS One 2014; 9(12): e114597.

Tables: 3

Figures: 0

References: 23

Received: 19.02.2016

Revised: 24.02.2016

Accepted: 02.03.2016

Address for correspondence:

Daria D. Chmielewska MD, PhD

Katedra Podstaw Fizjoterapii

Wydział Fizjoterapii AWF

ul. Mikołowska 72

40-062 Katowice

Polska

Tel.: +48 691 951-906

E-mail: d.chmielewska@awf.katowice.pl 